\title{
Long-term monitoring of deficit irrigation regimes on citrus orchards in Sicily
}

\author{
Daniela Vanella, ${ }^{1}$ Filippo Ferlito, ${ }^{2}$ Biagio Torrisi, ${ }^{2}$ Alessio Giuffrida, ${ }^{2}$ Salvatore Pappalardo, ${ }^{1}$ \\ Daniela Saitta, ${ }^{1}$ Giuseppe Longo-Minnolo, ${ }^{3}$ Simona Consoli ${ }^{1}$
}

\begin{abstract}
${ }^{1}$ Department of Agriculture, Food and Environment (Di3A), University of Catania, Catania; ${ }^{2}$ Council for Agricultural Research and Economics, Research Centre for Olive, Fruit and Citrus crops, Acireale (CT); ${ }^{3}$ International Doctorate in Agricultural, Food and Environmental Science Di3A, University of Catania, Catania, Italy
\end{abstract}

\begin{abstract}
The study aims to identify the responses of citrus orchards $(C$. sinensis (L.) Osbeck), grown under typical Mediterranean climatic conditions, to deficit irrigation (DI) regimes applied over more than a decade (2010-2020). In particular, the DI regimes were declined at the study site in terms of sustained deficit irrigation, regulated deficit irrigation, partial drying of the root-zone, with increasing severity of the water deficit, from $25 \%$ to $50 \%$ of the crop evapotranspiration, using surface and sub-surface micro-irrigation techniques. Long-term monitoring was set up for identifying the main processes acting at the soil-plant-atmosphere continuum (SPAC) level through direct in situ measurements of mass and energy fluxes (i.e., via micrometeorological technique) and the estimation of $\mathrm{ET}_{\mathrm{c}}$ and transpiration fluxes (i.e., via sap flow method), and the soil-plant-water processes (via geoelectrical techniques). In addition, the main physiological, qualitative, and quantitative parameters were evaluated since the beginning of the experiment. The results of the long-term experiment demonstrated the great adaptability of the crop species to sustain even the high-
\end{abstract}

Correspondence: Giuseppe Longo-Minnolo, International Doctorate in Agricultural, Food and Environmental Science Di3A, University of Catania, via S. Sofia 100, Catania 95123, Italy.

E-mail: giuseppe.longominnolo@phd.unict.it

Key words: Sustainable citrus production; Mediterranean climate; orange groves; water deficit.

Acknowledgements: the work was carried out in the frame of Programma Operativo Nazionale (PON) 'Attraction and International Mobility' (AIM) 1848200-2 initiative (D.V.) and within the project 'Strategie per migliorare l'efficienza d'uso dell'acqua per le colture mediterranee' (SaveIrriWater) Linea 2 Ricerca di Ateneo 2020-22 (Università degli Studi di Catania).

Received for publication: 22 April 2021.

Accepted for publication: 12 August 2021.

C) Copyright: the Author(s), 2021

Licensee PAGEPress, Italy

Journal of Agricultural Engineering 2021; LII:1193

doi:10.4081/jae.2021.1193

This article is distributed under the terms of the Creative Commons Attribution Noncommercial License (by-nc 4.0) which permits any noncommercial use, distribution, and reproduction in any medium, provided the original author(s) and source are credited. est water reductions without substantial alterations of the main marketable productive and qualitative characteristics, evidencing the importance of controlling the SPAC dynamics for correctly applying the water restriction regimes.

\section{Introduction}

Irrigated agriculture has to cope with the increasingly limited availability of water resources, which is becoming worrying, especially in Mediterranean arid and semi-arid areas due to climate change scenarios. In these environments, the success of citrus production largely depends on adequate irrigation supply (Consoli et al., 2014, 2017). Therefore, it is essential to manage the available water resources in a sustainable way to optimise the productivity of crops while enhancing their adaptation to water shortage conditions.

In this perspective, several studies have emphasised the role of localised irrigation techniques for citrus groves (e.g., surface and sub-surface drip irrigation) in combination with optimal management of irrigation water [e.g., deficit irrigation (DI), including partial root-zone drying (PRD), regulated deficient irrigation (RDI), and sustained deficit irrigation (SDI)] (e.g., Saitta et al., 2021 and references inside). It is known that DI strategies permit to maintain (or slightly reduce) crop production features by applying a considerably lower amount of irrigation volume, with the consequent increase of crop water use efficiency (WUE) (e.g., English, 1990). Adopting the RDI technique requires a deep knowledge of the physiological crop response to water deficit conditions to identify the optimal phenological phase for the application of water restrictions to minimise the negative effects on crop yield and quality (Lo Cicero et al., 2016). Considering the PRD strategy (i.e., irrigation is alternatively applied to only one half of the root zone, while the other half is kept dry), several studies have shown that in the root system under drying soil, biochemical signals are triggered by the roots to shoot, causing physiological responses for plant adaptation, such as stomatal conductance and plant transpiration reduction (e.g., La Malfa et al., 2011).

Citrus groves, prevalent crops in Mediterranean regions, are characterized by a particularly long productive vegetative cycle. During Summer, if soil moisture is limited and roots are unable to guarantee water supply, the evapotranspiration rate (ET) decreases and, consequently, growth decreases (e.g., Fereres and Soriano, 2007). Numerous researches have shown that the effectiveness of DI strategies depends on the phenological phase in which the stress is applied and on environmental factors (Capra et al., 2008; Consoli et al., 2014). In particular, the characteristics of the soilplant-atmosphere continuum (SPAC) (e.g., hydraulic characteris- 
tics of the soil, air temperature, ET rates) influence the opening and closing of stomata and, therefore, the assimilation of $\mathrm{CO}_{2}$ and its levels. Thus, accurate estimates of the flux transfer exchanges acting within the SPAC are needed to optimize DI criteria application. Among the numerous techniques proposed in the literature, micrometeorological methods, such as the eddy covariance (EC), quantify the actual $\mathrm{ET}\left(\mathrm{ET}_{\mathrm{EC}}\right)$ starting from the direct measurement of the latent heat flow (LE) above the foliage. However, the easiest and cheaper modelling approach used to estimate ET is the FAO56 method (Allen et al., 1998), including the single crop coefficient $\left(\mathrm{K}_{\mathrm{c}}\right)$ approach, and a more complex dual $\mathrm{K}_{\mathrm{c}}$ approach (basal crop coefficient, $\mathrm{K}_{\mathrm{cb}}$; and evaporation coefficient, $\mathrm{K}_{\mathrm{e}}$ ), that splits the ET in crop transpiration (T) and soil evaporation (E) (Allen et al., 1998). Both approaches account for climatic variables at the reference ET condition $\left(\mathrm{ET}_{0}\right)$ and crop type and its characteristics (included in $\mathrm{K}_{\mathrm{c}}$ and $\mathrm{K}_{\mathrm{cb}}$ ), whereas soil texture and hydraulic characteristics are included in $\mathrm{K}_{\mathrm{e}}$. Despite being the most widely used approach up to date, the methodology requires crop-specific coefficients and field validation in order to offer reliable estimates (Vanella et al., 2019). As reported in numerous studies, the adoption of the dual $\mathrm{K}_{\mathrm{c}}$ approach results more appropriate in applying DI scenarios, such as the partial zoot-zone drying (PRD) and the adoption of drip irrigation technologies (Saitta et al., 2020).

The main aim of this study was to prove the degree of adaptability of sweet orange on sustaining different levels of water deficit after a decade of DI applications in Sicily (Italy) under a Mediterranean semi-arid climate. The specific objectives of the study are the following: i) to assess the sustainability of PRD, RDI, and SDI integrated with surface and sub-surface micro-irrigation techniques in maintaining adequate physiological and productive crop responses; ii) to evaluate whether the integration among different methodologies is appropriate for accurately estimating the irrigated orchard's crop evapotranspiration $\left(\mathrm{ET}_{\mathrm{c}}\right)$ under the DI regime; iii) to evaluate the application of innovative tools for monitoring the soil-water status of the crops under study.

\section{Materials and methods}

\section{Study site and irrigation regimes}

The long-term monitoring of DI strategies application has been conducted in 1 ha orange orchard (Citrus sinensis (L.) Osbeck, Tarocco Sciara grafted on Carrizo citrange Poncirus trifoliata (L.) Raf. $\times$ C. sinensis (L.) Osbeck), located in Eastern Sicily (insular Italy; $37^{\circ} 20^{\prime} \mathrm{N}, 14^{\circ} 53^{\prime} \mathrm{E}$ ), since 2011 . At the beginning of the experiment, the plants were 3 years old and were planted with a spacing of $6.0 \mathrm{~m}$ (between-row) $\times 4.0 \mathrm{~m}$ (within-row). The study area is characterized by a Mediterranean climate with irregular rainfall (i.e., a yearly average of about $580 \mathrm{~mm}$ within 2002-2020) and an annual $\mathrm{ET}_{0}$ of about $1268 \mathrm{~mm}$.

Irrigation scheduling was defined on a weekly basis using the FAO-56 Penman-Monteith (P-M) approach (Allen et al., 1998). Precisely, the $\mathrm{ET}_{\mathrm{c}}$ estimates were calculated by multiplying the daily $\mathrm{ET}_{0}$ by the seasonal crop coefficient for orange orchard $\left(\mathrm{K}_{\mathrm{c}}\right.$, equal to 0.7 from Consoli et al., 2006) and other coefficients, including a localized factor $\left(\mathrm{K}_{1}\right)$ and other irrigation technological factors (i.e., referring to the irrigation efficiency and uniformity of the used drip irrigation system, ranging between 90 and 95\%). At the beginning of each irrigation season, $\mathrm{K}_{1}$ was estimated as a function of the canopy area (i.e., fixed to 0.7 for the irrigation season 2020, Consoli et al., 2017).

During the long-term experiment, irrigation was supplied, following a randomized block design (Figure 1), generally from midJune to the end of September, 3 times per week, early in the morning (in 2020, day-of-the-year, DOYs 160-275). Irrigation phases were eventually skipped when rain occurrence fulfilled the $\mathrm{ET}_{\mathrm{c}}$ needs. Details on the experimental irrigation design are reported in Consoli et al. (2014). In particular, irrigation treatments included: i) a fully irrigated treatment (FI), where irrigation rate was supplied at $100 \%$ of $\mathrm{ET}_{\mathrm{c}}$ using two drip lines located close to the trunk, each characterized by a flow rate of $4 \mathrm{~L} \mathrm{~h}^{-1}$ per emitter, with

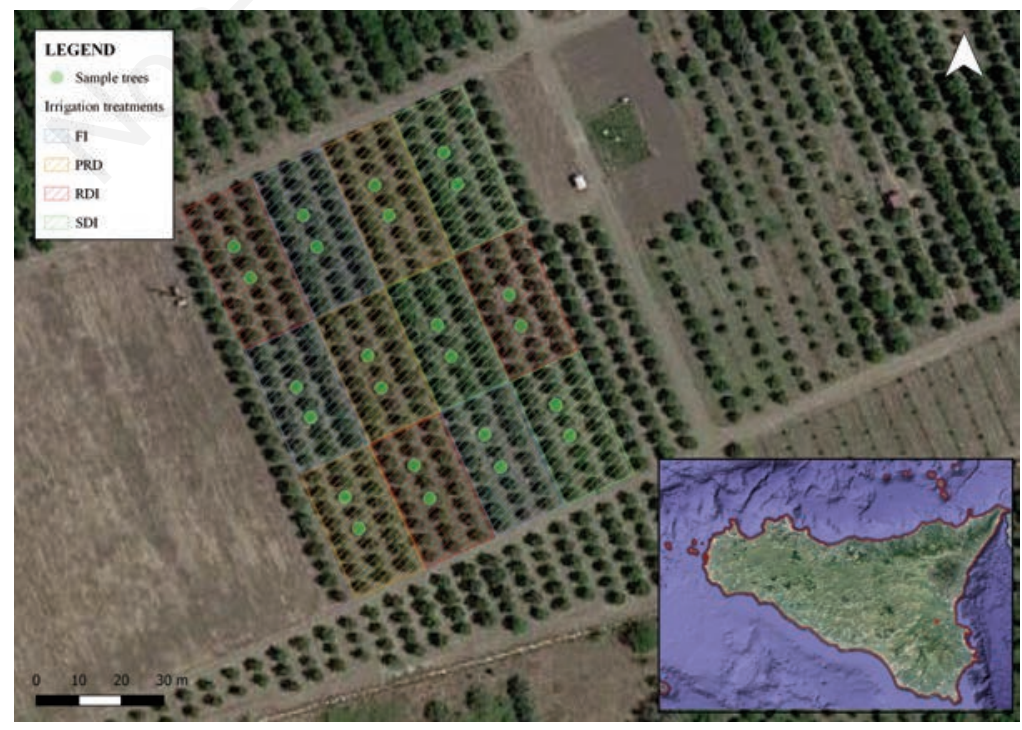

Figure 1. Experimental irrigation design with the location of the sample trees for the monitoring campaigns (FI, full irrigation; SDI, sustained deficit irrigation; RDI, regulated deficit irrigation; PRD, partial root drying). Details on the experimental setup are given in Consoli et al. (2014). 
12 emitters per tree; ii) an SDI treatment irrigated at $75 \%$ of $\mathrm{ET}_{\mathrm{c}}$, using two buried drip lines (located at $0.35 \mathrm{~m}$ from the soil surface), characterized by a flow rate of 2 and $4 \mathrm{~L} \mathrm{~h}^{-1}$, distributing a total of $36 \mathrm{~L} \mathrm{~h}^{-1}$ per tree; iii) an RDI treatment (RDI), irrigated at $100 \%$ of $\mathrm{ET}_{\mathrm{c}}$, except during the fruit growth phase, when irrigation was supplied at $50 \%$ of $\mathrm{ET}_{\mathrm{c}}$, emitting a total of 36 or $24 \mathrm{~L} \mathrm{~h}^{-1}$ per tree using two surface drip line as in FI; iv) a PRD treatment (PRD) irrigated at $50 \%$ of $\mathrm{ET}_{\mathrm{c}}$, where wet and dry sides of the root-zone were alternated every 7 days using two drip lines, emitting a total of $24 \mathrm{~L} \mathrm{~h}^{-1}$ per tree. Each dripper was spaced at $0.6 \mathrm{~m}$ on the irrigation lines. During the irrigation seasons, the amount of irrigation volume applied and the water pressure regime was measured using in-line water meters and manometers, respectively. Figure 2 shows the irrigation volumes supplied during the long-term application of the DI strategies in the experimental field (from 2011 to 2020). Average water savings (WS, \%), calculated as in Eq. 1, reached 22 $\%, 26 \%$, and $48 \%$ in SDI, RDI, and PRD, respectively:

$$
W S=\left(1-\frac{\text { irrigation rates in } S D I, R D I \text { or } P R D}{\text { irrigation rate in } F I}\right) * 100
$$

The soil water content (SWC) evolution has been measured on an hourly basis and averaged at daily scale at the different irrigation treatments using ECH2O probes (Decagon, Inc., Pullman, WA, USA). Details on the setup of the SWC sensors and soil characteristics (i.e., sandy loam texture) are reported in Consoli et al. (2014, 2017) and Puglisi et al. (2019). Water supplied for irrigation was characterized by a medium salinity (electrical conductivity of about $2.0 \mathrm{dSm}^{-1}$ ) and $\mathrm{pH}$ of about 7.0. In addition, soil texture and hydraulic characteristics were investigated within the profile 0.05 $0.25 \mathrm{~m}$. From laboratory determinations, soil samples were fairly uniform, with a sandy-loam texture. The soil field capacity (FC) and permanent wilting point (WP) were $28 \%$ and $14 \%$, respectively (D'Emilio et al. 2018).

\section{Long-term monitoring of the soil-plant-atmosphere continuum}

\section{Eddy Covariance evapotranspiration fluxes}

An EC tower was installed at the study site in 2016 (Vanella and Consoli, 2018). The EC instrumentation consisted of one three-dimensional (3-D) sonic anemometer (CSAT3-3D, Campbell Scientific Inc., Logan, UT, USA) and one infrared open-path gas analyser (Li-7500, Li-cor Biosciences Inc., Lincoln, Nebraska) to measure high-frequency data $(10 \mathrm{~Hz})$, including wind components and gas concentrations $\left(\mathrm{H}_{2} \mathrm{O}\right.$ and $\left.\mathrm{CO}_{2}\right)$, respectively. According to the procedure described in Saitta et al. (2020), the EC flux footprint was calculated using a cross-sectional approach, which considers the atmospheric stability, measurement height, surface roughness length, and lateral flux dispersion.

The standard EUROFLUX corrections and data processing procedures (Aubinet et al. 1999) were applied to the high-frequency data for determining the turbulent EC fluxes (latent heat flux, LE, and sensible heat flux, H), as follows:

$H=\rho \cdot c_{p} \cdot \sigma_{w T}$

$L E=\lambda \cdot \sigma_{w q}$

where, $\rho$ is the air density $\left(\mathrm{g} \mathrm{m}^{-3}\right)$; $\mathrm{c}_{\mathrm{p}}$ is the air specific heat capacity at constant pressure $\left(\mathrm{J} \mathrm{g}^{-1} \mathrm{~K}^{-1}\right)$; $\sigma_{\mathrm{WT}}$ is the covariance between the vertical wind speed and air temperature $\left(\mathrm{m} \mathrm{s}^{-1} \mathrm{~K}\right) ; \lambda$ is the latent heat of vaporization $\left(\mathrm{J} \mathrm{g}^{-1}\right)$, and $\sigma_{\mathrm{wq}}$ is the covariance between the vertical wind speed and water vapour density $\left(\mathrm{g} \mathrm{m}^{-2}\right.$ $\left.\mathrm{s}^{-1}\right)$.

In addition, the available energy $\left(R_{n}-G\right)$, i.e., net radiation $\left(R_{n}\right.$, $\mathrm{W} \mathrm{m}^{-2}$ ) and soil heat flow $\left(\mathrm{G}, \mathrm{W} \mathrm{m}^{-2}\right)$, were measured at low frequency $(30 \mathrm{~min}$ ) using one net radiometer placed $7 \mathrm{~m}$ above the ground (CNR-1 Kipp and Zonen, Delft, Netherlands) and the average of three self-calibrated soil heat flux plates (HFP01SC, Hukseflux, Delft, Netherlands) placed in the exposed, halfexposed, and shadowed soil, at a depth of about $0.05 \mathrm{~m}$. High and low-frequency data were recorded and managed by a CR1000 logger (Campbell Scientific Inc.).

The observed surface energy balance fluxes were checked by comparing the sum-up of the turbulent EC fluxes (LE and $\mathrm{H}$ ) with the available energy $\left(R_{n}-G\right)$, as follows:

$$
C F=\frac{L E+H}{R_{n}-G}
$$

where, $\mathrm{CF}$ is the energy-closure fraction; $\mathrm{LE}, \mathrm{H}, \mathrm{R}_{\mathrm{n}}$, and $\mathrm{G}$ represent the semi-hourly latent heat flux, sensible heat flux, net radiation, and soil heat flux components of the surface energy balance.

Half-hourly surface energy balance fluxes $\left(R_{n}, G, H\right.$, and LE) were aggregated daily scale, and LE rates were then transformed to an equivalent rate of actual ET $\left(\mathrm{ET}_{\mathrm{EC}}, \mathrm{mm} \mathrm{d}^{-1}\right)$. The lack of closure (Figure 3), which indicates the inconsistency and lack of strength of EC data, was about $22 \%$ during the last irrigation seasons 2018 2020 (June 1 - September 30), providing evidence for the validity of the obtained $\mathrm{ET}_{\mathrm{EC}}$ measurements.

\section{Sap flow estimates}

Water consumption at the tree level was continuously measured using the heat pulse velocity (HPV) sap flow technique (Swanson and Whitfield, 1981). In general, the HPV technique is based on the measurement of temperature variations $(\Delta T)$, produced by a heat pulse of short duration (1-2 s), in a couple of temperature probes installed asymmetrically on either side of a linear heater that is inserted into the trunk. Semi-hourly data were processed according to Motisi et al. (2012) for integrating the sap flow velocity over sapwood area for the T flux estimations, then aggregated at hourly and daily scales within the irrigation season 2020 (DOYs 160-275). Details of the adopted sap flow sensors and the descriptions of the methodological approaches are reported in Consoli et al. $(2014,2017)$ and Saitta et al. (2020; 2021).

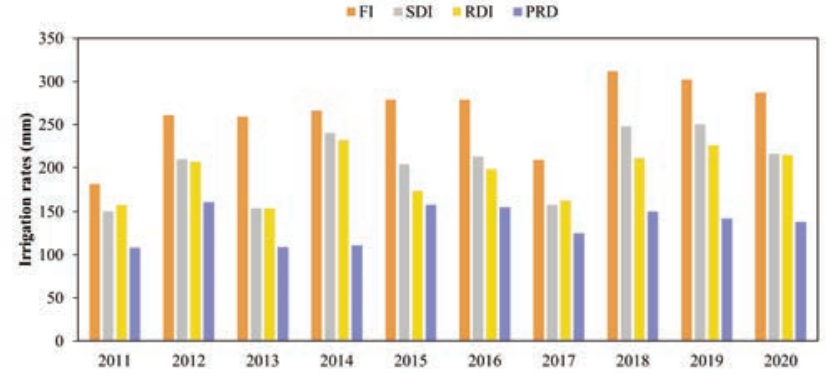

Figure 2. Irrigation rates (mm) supplied at the different treatments during the long-term deficit irrigation period (2011-2020) (FI, full irrigation; SDI, sustained deficit irrigation; RDI, regulated deficit irrigation; PRD, partial root drying). 
The use of electrical resistivity tomography to identify soil-root interactions

Electrical resistivity (ER) methods (e.g., electrical resistivity tomography, ERT - see, e.g., Binley and Kemna, 2005 - electrical resistivity imaging, ERI, and mise-a-la-masse, MALM) were intensively applied both in static and time-lapse mode at the study site using a Syscal Pro Switch 72 resistivity meter (IRIS Instruments). These methods have allowed determining the soil resistivity distribution, which represents an indirect proxy of soil properties and states (e.g., soil porosity, SWC, and pore water salinity). In general, ER methods are based on injecting an electrical current in the subsoil by a pair of electrodes and the subsequent measurement of the electrical potential. This acquisition is repeated through many combinations of transmitting and receiving electrodes in order to acquire data that can then be inverted to produce two-dimensional (Vanella et al. 2020) or 3-D (e.g., Consoli et al., 2017; Mary et al., 2019; Puglisi et al., 2019; Vanella et al., 2018, 2019) ER images of the subsoil. Borehole electrodes enhance resolution at depth (Consoli et al., 2017; Puglisi et al., 2019; Vanella et al., 2018, 2019). In this study, the finding of a 3-D ERT survey is provided as an example of non-invasive monitoring tool that can be applied for capturing the subsurface soil-water variability. In particular, the used ERT setup consisted of 72 electrodes (including 24 surface and 48 buried electrodes) bordering the root zone of two orange trees located at the study site both under FI and PRD conditions. The ERT acquisitions were performed before the irrigation phase (time 00) and in time-lapse mode during an irrigation test conducted on July 29, 2016.

\section{Physiological measurements, production responses, and water use efficiencies}

Plant water status has been monitored by measuring stem water potential $\left(\Psi_{\text {stem }}\right)$ with a pressure chamber (SKPM 1405/40, SkyeInstruments, UK) (Scholander et al., 1965) since the beginning of the application of the water regimes understudy in 2011. Measurements were performed twice a month during the irrigation period (June-September) on fully exposed sunlit leaves (i.e., generally at mid-day); leaves were wrapped in plastic bags and covered with silver foil for at least one hour prior to measurements. A total of six trees per treatment and two leaves per tree were analysed (Figure 1).

Responses of orange trees to DI regimes were monitored at the harvest periods (February-March) in terms of fruit yield (i.e., yield, fruit weight, and equatorial diameter-ED) and quality (i.e., titratable acidity, TA and total soluble solids, TSS) using the standard methods proposed by Kimball (1999). The main quality features were obtained at harvest time by analysing ten fruits per tree from twelve trees per treatment and replication.

The water use efficiency (WUEY) was determined as a ratio between yield $(\mathrm{kg})$ and irrigation volume applied per unit area $\left(\mathrm{mm} \mathrm{ha}^{-1}\right)$ for evaluating and comparing the impact of the different DI regimes on the productive features of the orange trees. Similarly, WUE was estimated based on the qualitative features as the ratio between TA and TSS ( $\mathrm{g}$ ) and irrigation volume distributed $\left(\mathrm{m}^{3}\right)$, named as WUETA and WUETSS, respectively.

The 'Statistica' software package (version 6.0, Statsoft Inc.) was applied for data analysis, and the analysis of variance (ANOVA) was performed, with means separated by Tukey HSD test at probability levels $(\mathrm{P})$ of $0.001,0.01$, and 0.05 .

\section{Results and discussion}

Numerous methodologies have been applied at the study site during the long-term monitoring 2010-2020 for characterizing both the surface energy balance fluxes acting within the SPAC system and the crop response under DI conditions. As showed in Figure 4, these methodologies have included micrometeorological measurement techniques combined with estimation models based on satellite-type approaches for deriving the $\mathrm{ET}_{\mathrm{EC}}$ and $\mathrm{ET}_{\mathrm{c}}$ at the study site (Vanella and Consoli, 2018). In addition, these approaches have offered the best performance when integrated with ancillary data referring to soil and weather characteristics. Specifically, Vanella et al. (2019) reported that the combined use of geophysical techniques for tracking the soil wetting distribution patterns and satellite information improved the $\mathrm{ET}_{\mathrm{c}}$ estimations using the dual FAO-56 approach (Allen et al., 1998). In addition, the implementation of using the dual FAO-56 approach with weather forecast data provided slight overestimates of $\mathrm{ET}_{\mathrm{c}}$ estimates compared with the use of measured meteorological data (Longo-Minnolo et al., 2020). These findings offer the possibility of employing alternative soil and weather data sources in addition to the use of traditional ground-based observations.

With reference to the more recent irrigation season (2020, day-

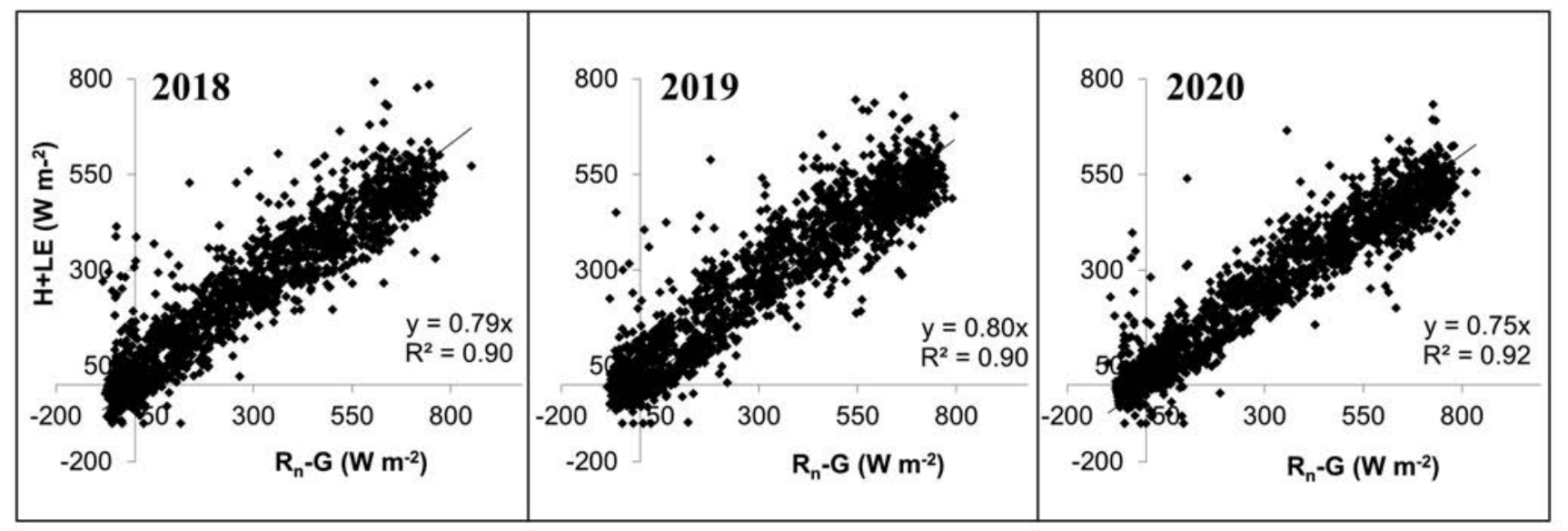

Figure 3. Energy balance closure referring to the irrigation seasons 2018-2020 (June 1 - September 30 periods). 
of-the-year, DOYs 160-275), the daily average ( \pm standard deviation) $\mathrm{ET}_{\mathrm{EC}}$ and $\mathrm{T}$ rates were $2.6 \pm 0.6$ and $1.0 \pm 0.2 \mathrm{~mm} \mathrm{~d}^{-1}$, respectively (Figure 5). During the same season, the daily average ( \pm standard deviation) $\mathrm{ET}_{0}$ and $\mathrm{ET}_{\mathrm{c}}$ fluxes calculated by the P-M FAO single $\mathrm{K}_{\mathrm{c}}$ approach were $5.5 \pm 1.5$ and $2.7 \pm 0.7 \mathrm{~mm} \mathrm{~d}^{-1}$, respectively. Interestingly, the same decreasing temporal patterns observed for the $\mathrm{T}$ and $\mathrm{ET}_{\mathrm{c}}$ fluxes were mainly driven by the reduction of the atmospheric demand $\left(\mathrm{ET}_{0}\right)$ during the reference period. On the other hand, ETEC fluxes showed great variation throughout the season (from 1.30 to $4.90 \mathrm{~mm} \mathrm{~d}^{-1}$ ), which was mainly associated with rainfall events (Maestre-Valero et al., 2017). Figure 5 also showed the daily average SWC values observed in the upper soil layer $(0.10-0.30 \mathrm{~m})$ at the level of the treatment. As expected, all irrigation treatments had daily SWC values ranging between the FC and the WP, showing similar average daily SWC conditions, varying from 0.21 (for SDI and PRD) to $0.22 \mathrm{~cm}^{3} \mathrm{~cm}^{-3}$ (for FI and FI RDI).

As reported in Figure 4, during the long-term monitoring (from 2015 to 2020), geophysical techniques (including ERT, ERI, and MALM) were successfully applied at the study site in order to identify the roots interactions and mass exchanges in the soil-plant system at the different irrigation regimes (refer to Consoli et al., 2017; Mary et al., 2019, Vanella et al., 2018, 2019, 2020). As an example, Figure 6 shows the ERT acquisition time steps and the hourly ETEC rates measured at the study site together with the 3-D time-lapse ER images obtained during an irrigation test conducted under FI (B and C) and PRD conditions (D and E). Specifically, the
3-D time-lapse ER images show the identified ER changes (in terms of ER increasing or decreasing patterns) observed at finer spatial and temporal scale at selected time steps (time 01 and 02 , Figure 6A) in comparison with the initial condition (before irrigation, time 00, Figure 6A). The ER decreases were evident in the soil volumes of both the explored treatments (FI and PRD) during the irrigation phase, allowing to track the irrigation infiltration progresses in depth (Figure 6B-E). At FI, the soil volume affected by ER changes was $50 \%$ greater than that in PRD; this may be associated with the smaller soil volume explored by the root system of PRD trees. In addition, the observed ER increases in FI at time 02 (Figure 6C) can be related to the root water uptake process; thus, they followed the same temporal evolution of ETEC fluxes (Figure 6A) (data refers to July 29, 2016), giving useful information about time-varying nature of the soil-plant system.

In general, crop response monitoring plays a fundamental role in adopting sustainable irrigation criteria (Adeyemi et al., 2017). During the long-term monitoring at the study site (2010-20), some plant-based water status parameters were tested, such as $\Psi_{\text {stem, }}$ stomatal conductance, sap flow, leaf photosynthesis, and canopy temperature (refer to Saitta et al., 2021 and reference inside). In general, from a physiological point of view, $\Psi_{\text {stem variations occur }}$ when soil water potential is reduced, and leaf stomata adjust leaf gas exchange through partial closure (Klein, 2014). Although several physical and chemical signals trigger stomatal closure, it is well-known in the literature that the interspecific feedback mecha-

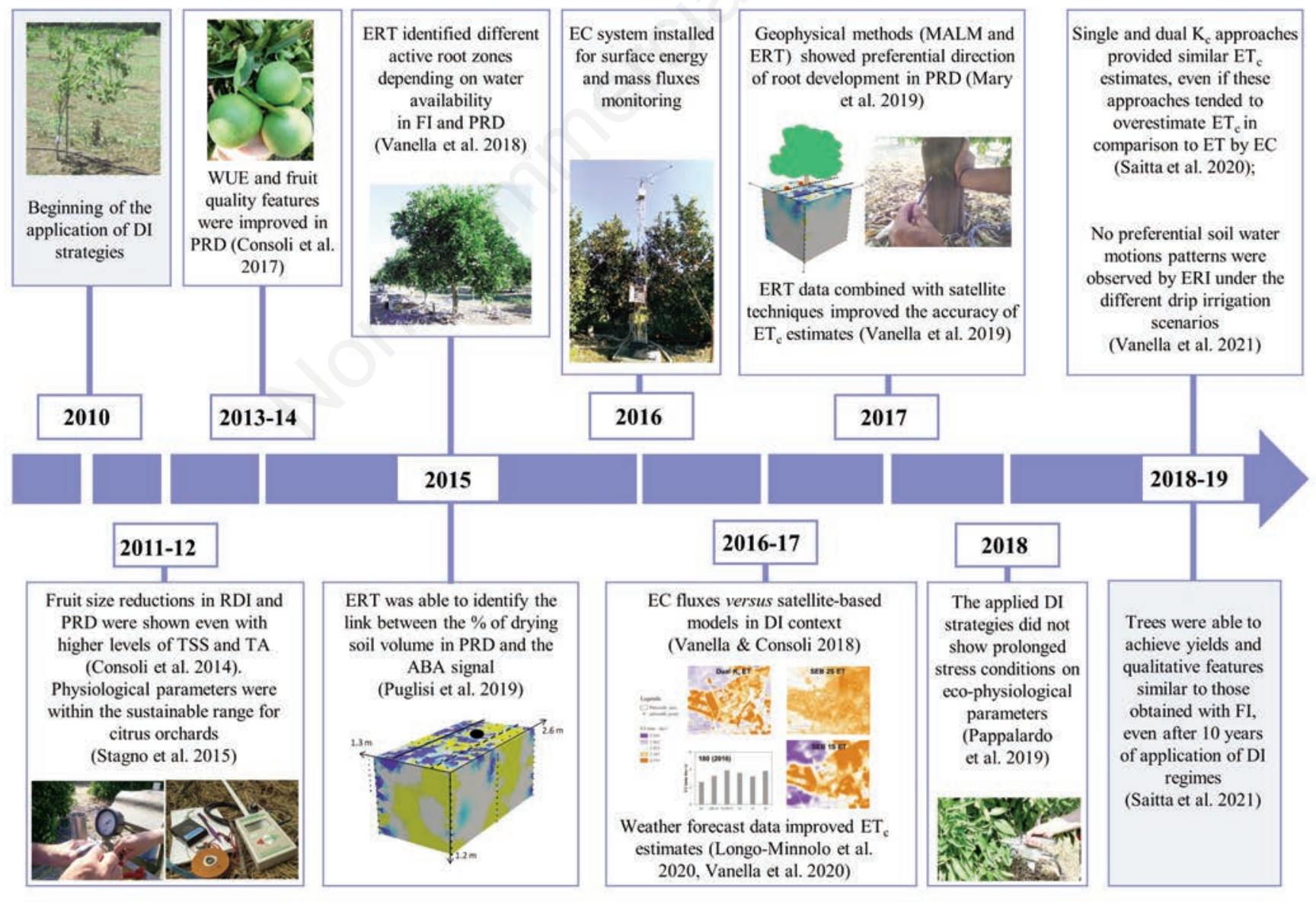

Figure 4. Timeline of the experimental activities carried out at the study site. 


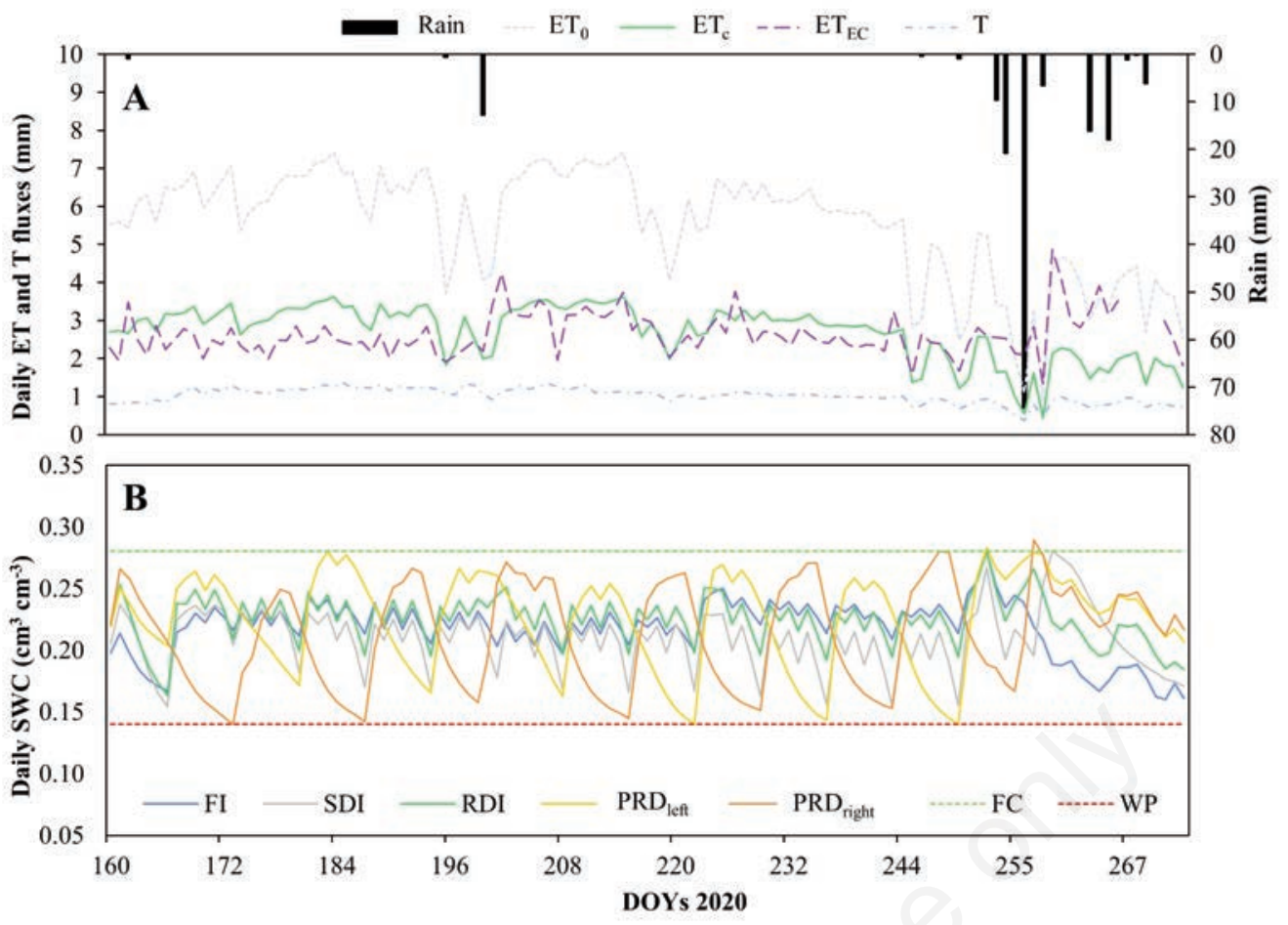

Figure 5. (A) Daily evapotranspiration (ET; reference ET, ET 0 ; crop ET, ET ; and actual ET, ETEC) and transpiration (T) fluxes measured and estimated at the experimental site during the irrigation season 2020 (day-of-the-year, DOYs 160-275); (B) daily soil water content (SWC, $\mathrm{cm}^{3} \mathrm{~cm}^{-3}$ ) observed at the different irrigation treatments (FI, full irrigation; SDI, sustained deficit irrigation; RDI, regulated deficit irrigation; PRD, partial root-zone drying, including on the left and right sides of the PRD system, PRDleft, and PRD right, respectively). FC and WP refer to the field capacity and permanent wilting point, respectively.

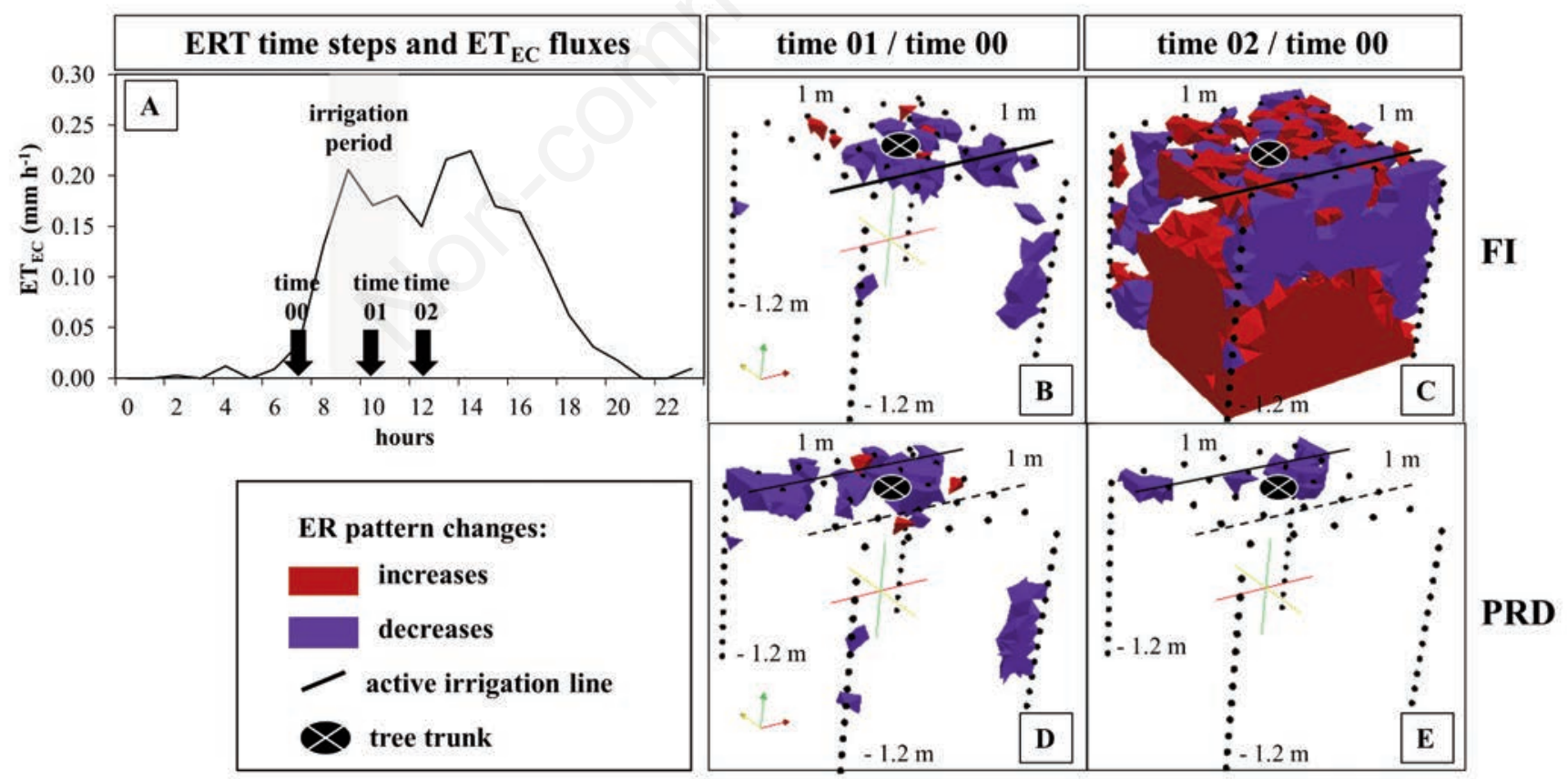

Figure 6. (A) Electrical resistivity tomography (ERT) dataset acquisition time steps and hourly actual evapotranspiration fluxes (ETEC, $\mathrm{mm} \mathrm{h}^{-1}$ ) measured by eddy covariance (EC) technique at the study site; (B-E) Electrical resistivity (ER) changes corresponding to increase and decrease of ER at full irrigation (FI) and partial root-zone drying (PRD) conditions at two selected time instants (time 01 and time 02) in comparison to time 00. Data refer to July 29, 2016. 
nism between $\Psi_{\text {stem }}$ and stomatal conductance is crop-dependent (Ortuño et al., 2006; Zhang et al., 2013). Therefore, among the analysed plant-based parameters, $\Psi_{\text {stem }}$ was identified as the most representative for evaluating the citrus water status understudy. In fact, significant correlations were evidenced in Saitta et al. (2021) between sap flow and $\Psi_{\text {stem values, indicating specific clusters }}$ mainly as a function of the different $\mathrm{T}$ rates due to the different degrees of water deficits applied at the study site.

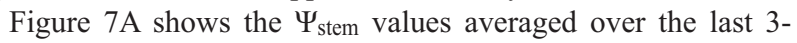
years of the trial (2018-2020) at the irrigation treatments (JuneSeptember periods). The average $\Psi_{\text {stem values and their standard }}$ deviations show minimal and not significant variations among the treatments, with significant differences observed only between the control (FI) and the most stressed treatment (PRD, 50\% of water deficit). The annual mean values of $\Psi_{\text {stem varied from }-1.50 \text { in FI }}$ (full irrigation) to a minimum of $-1.89 \mathrm{MPa}$ in $\mathrm{PRD}$ (with $50 \% \mathrm{ET}_{\mathrm{c}}$ of water supply). This finding testifies how over time, the crops have developed an important strategy of adaptation to the conditions of irrigation volumes reduction without causing adverse effects on the yield and fruit quality (Saitta et al., 2021). However, the hypothesis that citrus trees can be supplied by external water inputs (e.g., rain and capillary rise from shallow groundwater) cannot be excluded.

Figure 7B-F reports the main productive and qualitative plant features identified during the most significant harvest campaigns (2018-2021). As can be seen from this figure, the different irrigation treatments did not show differences in the main quantitative (yield and fruit weight, Figure 7B-C) during the last harvests, except for ED observed at harvest 2020-21 (Figure 7D), that showed higher values for PRD $(86.5 \pm 2.9 \mathrm{~mm})$ in comparison to FI $(79.3 \pm 3.0 \mathrm{~mm})$. This significant difference may not be related to the application of water restrictions regimes as observed by García-Tejero et al. (2010) under the DI context. Furthermore, it is interesting to note that the average ED values were always greater than the minimum marketable diameter (i.e., 73-84 mm for blood orange). No differences were observed in the qualitative (TSS and TA, Figure 7E-F) parameters. These results testified to the economic sustainability of the irrigation regimes applied. In order to summarize the results of the study, Table 1 shows the WUE parameters obtained for the harvest 2020-21, which can well highlight

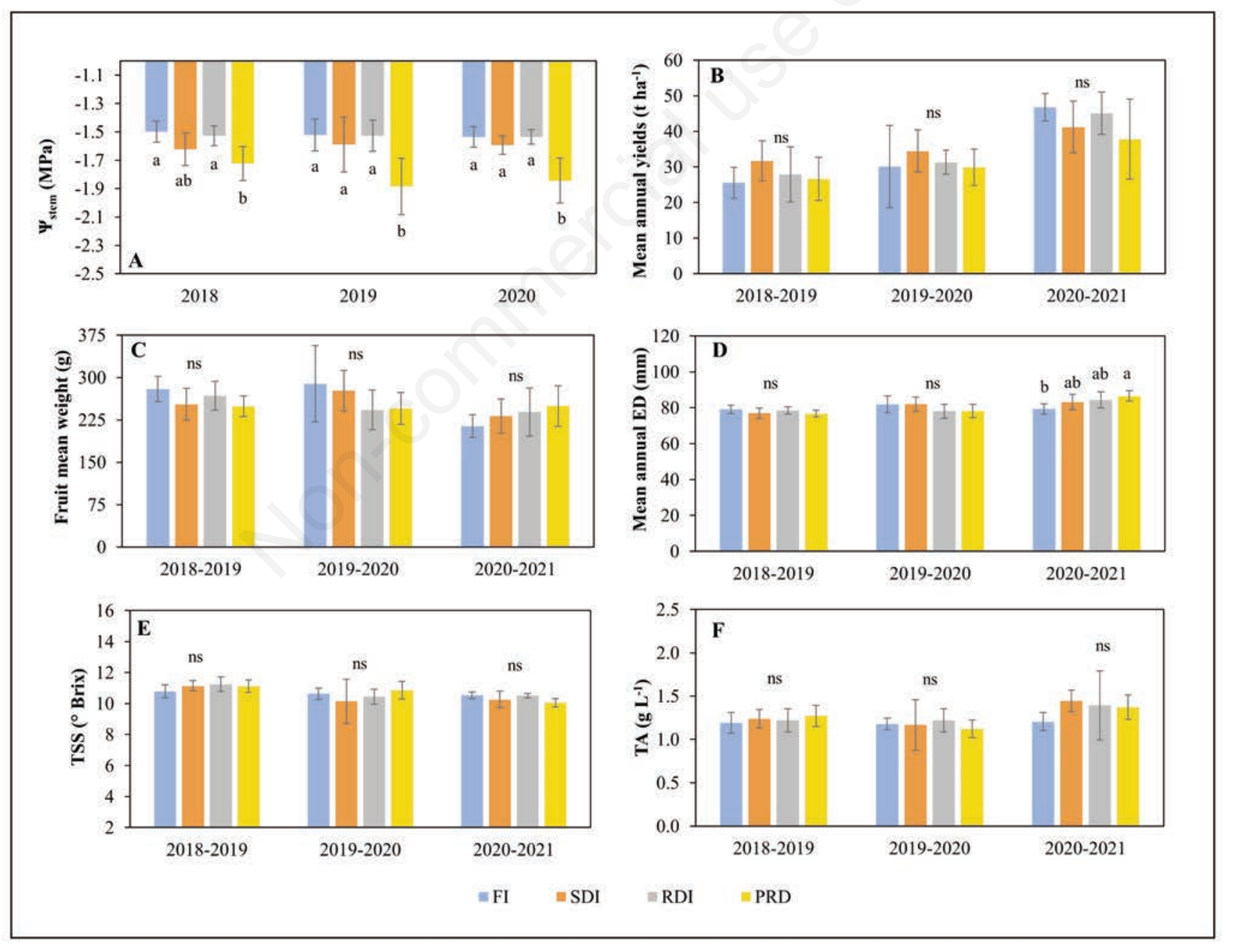

Figure 7. (A) Mean stem water potential ( $\Psi_{\text {stem, }}$ MPa) values (and standard deviations) during the monitoring irrigation periods 201820; (B) yield $\left(\mathrm{t} \mathrm{ha}^{-1}\right),(\mathrm{C})$ fruit weight $(\mathrm{G}),(\mathrm{D})$ equatorial diameter $(\mathrm{ED}, \mathrm{mm})$, (E) total soluble solids (TSS, Brix) and (F) titratable acidity (TA, $\left.\mathrm{g} \mathrm{L}^{-1}\right)$ monitored during the harvest phases (2019-21) at the study site. Different letters indicate statistically significant differences among the irrigation treatments for each year according to Tukey's test $(P \leq \mathbf{0 . 0 5})$. ns, not significant. 
Table 1. Effect of irrigation treatments on water use efficiency on yield (WUEY) and titratable acidity (WUETA) and total soluble solids (WUETSS) and their standard error at harvest 2020-21.

\begin{tabular}{lcccc} 
WUE parameters & FI & SDI & RDI & PRD \\
WUEY $\left(\mathrm{kg} \mathrm{m}^{-3}\right)$ & $9.1 \pm(0.4)^{\mathrm{b}}$ & $13.4 \pm(1.0)^{\mathrm{ab}}$ & $11.7 \pm\left(1.6^{\mathrm{ab}}\right.$ & $23.0 \pm 5.3^{\mathrm{a}}$ \\
WUETA $\left(\mathrm{g} \mathrm{m}^{-3}\right)$ & $103.84 \pm 5.9^{\mathrm{b}}$ & $160.54 \pm 14.0^{\mathrm{b}}$ & $152.62 \pm 21.3^{\mathrm{b}}$ & $262.24 \pm 32.2^{\mathrm{a}}$ \\
\hline WUETSS $\left(\mathrm{g} \mathrm{m}^{-3}\right)$ & $907.98 \pm 41^{\mathrm{b}}$ & $1133.57 \pm 83^{\mathrm{b}}$ & $1143.22 \pm 48^{\mathrm{b}}$ & $1918.70 \pm 211^{\mathrm{a}}$ \\
\hline
\end{tabular}

FI, full irrigation; SDI, sustained deficit irrigation; RDI, regulated deficit irrigation; PRD, partial root-zone drying. ${ }^{\text {ab }}$ Different letters indicate statistically significant differences among the irrigation treatments for each year according to Tukey's test $(\mathrm{P} \leq 0.05)$.

the positive results achieved by applying the DI strategies. In particular, the WUEY values for harvest 2020-21 showed significant differences between FI and PRD (23.0 versus $11.4 \mathrm{~kg} \mathrm{~m}^{-3}$ ) as reported in Saitta et al. (2020) for the previous harvests 2018-19 and 2019-20. A similar trend was observed at harvest 2020-21 for WUE $_{T A}$ and WUETSS, which showed significantly higher values in the most severe water deficit regime (PRD) than those referring to the other irrigation treatments. In particular, WUETA values were 262.2 and $139.0 \pm 10.26 \mathrm{~g} \mathrm{~m}^{-3}$, for PRD and the average ( \pm standard error values) among FI, SDI, and RDI treatments; and WUETSS values were equal to 1918.70 versus $1061.6 \pm 41.89 \mathrm{~g} \mathrm{~m}^{-3}$, respectively. These results are in accordance with those obtained for the irrigation season 2020 (Saitta et al., 2021).

\section{Conclusions}

The main conclusions that can be drawn from the long-term monitoring as reported as follows:

- The use of DI strategies (PRD, RDI, SDI) integrated with drip irrigation technologies has permitted to maintain sustainable physiological and productive crop responses and to enhance the efficient use of water by citrus crops, reaching water savings of $48 \%$;

- Multi-approach methods have provided accurate ET fluxes using both measurement (eddy covariance and sap flow methods) and modelling approaches (P-M method) under DI conditions;

- The application of innovative tools for soil-plant monitoring (ERT) has provided fine-scale spatial and temporal images of the subsoil changes driven by irrigation and the soil water redistribution processes under FI and DI conditions.

\section{References}

Adeyemi O., Grove I., Peets S., Norton T. 2017. Advanced monitoring and management systems for improving sustainability in precision irrigation. Sustainability 9:353.

Allen R.G., Pereira L.S., Raes D., Smith M. 1998. Crop evapotranspiration. Guidelines for computing crop water requirements. Irrigation and Drainage Paper 56, 300 (9), D05109. Food and Agriculture Organization, Rome, Italy.

Aubinet, M., Grelle, A., Ibrom, A., Rannik, Ü., Moncrieff, J., Foken, T., Kowalski, A.S., Martin, P.H., Berbigier, P., Bernhofer, Ch., Clement, R., Elbers, J., Granier, A., Grünwald, T., Morgenstern, K., Pilegaard, K., Rebmann, C., Snijders, W., Valentini, R., Vesala, T. (1999). Estimates of the annual net carbon and water exchange of forests: the EUROFLUX methodology. Advances in ecological research, 30, 113-175.

Binley A.M., Kemna A. 2005: DC resistivity and induced polariza- tion methods. In: Rubin Y. and Hubbard S.S. (Eds.), Hydrogeophysics. Water Sci. Technol. Library, Ser. 50. Springer, New York, NY, USA, pp. 129-156.

Capra A., Consoli S., Russo A., Scicolone B. 2008: Integrated agro-economic approach to deficit irrigation on lettuce crops in Sicily (Italy). J. Irrig. Drain. Eng. 134:437-45.

Consoli S., O’Connell N., Snyder R. 2006. Measurement of light interception by navel orange orchard canopies: case study of Lindsay, California. J. Irrig. Drain. Eng. 132:9-20.

Consoli S., Stagno F., Roccuzzo G., Cirelli G.L., Intrigliolo F. 2014. Sustainable management of limited water resources in a young orange orchard. Agric. Water Manag. 132:60-8.

Consoli S., Stagno F., Vanella D., Boaga J., Cassiani G., Roccuzzo G. 2017. Partial root-zone drying irrigation in orange orchards: effects on water use and crop production characteristics. Eur. J. Agron. 82:190-202.

D’Emilio A., Aiello R., Consoli S., Vanella D., Iovino M. 2018. Artificial neural networks for predicting the water retention curve of sicilian agricultural soils. Water 10:1431.

English M.J. 1990. Deficit irrigation: an analytical framework. J. Irrig. Drain. Eng. 116:399-412

Fereres E., Soriano M.A. 2006. Deficit irrigation for reducing agricultural water use. J. Exp. Bot. 58:147-59.

García-Tejero I., Jiménez-Bocanegra J.A., Martínez G., Romero R., Durán-Zuazo V.H., Muriel-Fernández J.L. 2010. Positive impact of regulated deficit irrigation on yield and fruit quality in a commercial citrus orchard [Citrus sinensis (L.) Osbeck, cv. salustiano]. Agric. Water Manage. 97:614-22.

Kimball D. 1999. Citrus processing: a complete guide. 2nd ed. Springer, Boston, MA, USA.

Klein T. 2014. The variability of stomatal sensitivity to leaf water potential across tree species indicates a continuum between isohydric and anisohydric behaviours. Funct. Ecol. 28:1313-20.

La Malfa S., Distefano G., Domina F., Nicolosi E., Toscano V., Gentile A. 2011. Evaluation of citrus rootstock transgenic for rolABC genes. Acta Hortic. 892:131-40.

Lo Cicero L., Puglisi I., Nicolosi E., Gentile A., Ferlito F., Continella A., Lo Piero A.R. 2016. Anthocyanin levels and expression analysis of biosynthesis-related genes during ripening of Sicilian and international grape berries subjected to leaf removal and water deficit. J. Agr. Sci. Tech. 18:1333-44.

Longo-Minnolo G., Vanella D., Consoli S., Intrigliolo D.S., Ramírez-Cuesta J.M. 2020. Integrating forecast meteorological data into the $\mathrm{ArcDualK}_{\mathrm{c}}$ model for estimating spatially distributed evapotranspiration rates of a citrus orchard. Agric. Water Manag. 231:105967.

Maestre-Valero J.F., Testi L., Jiménez-Bello M.A., Castel J.R., Intrigliolo D.S. 2017. Evapotranspiration and carbon exchange in a citrus orchard using eddy covariance. Irrig. Sci. 35:397408.

Mary B., Vanella D., Consoli S., Cassiani G. 2019. Assessing the extent of citrus trees root apparatus under defcit irrigation via 
multi-method geo-electrical imaging. Sci. Rep. 9:1-10.

Motisi A., Rossi F., Consoli S., Papa R., Minacapilli M., Rallo G., Cammalleri C., D'Urso G. 2012. Eddy covariance and sap flow measurement of energy and mass exchanges of woody crops in a Mediterranean environment. Acta Hortic. 951:121-7.

Ortuno, M. F., García-Orellana, Y., Conejero, W., Ruiz-Sánchez, M. C., Alarcón, J. J., \& Torrecillas, A. (2006). Stem and leaf water potentials, gas exchange, sap flow, and trunk diameter fluctuations for detecting water stress in lemon trees. Trees, 20(1), 1-8.

Puglisi I., Nicolosi E., Vanella D., Lo Piero A.R., Stagno F., Saitta D., Roccuzzo G., Consoli S., Baglieri A. 2019. Physiological and biochemical responses of orange trees to different deficit irrigation regimes. Plants 8:423.

Saitta D., Consoli S., Ferlito F., Torrisi B., Allegra M., LongoMinnolo G., Ramírez-Cuesta J.M., Vanella D. 2021. Adaptation of citrus orchards to deficit irrigation strategies. Agric. Water Manag. 247:106734.

Saitta D., Vanella D., Ramírez-Cuesta J.M., Longo-Minnolo G., Ferlito F., Consoli S. 2020. Comparison of orange orchard evapotranspiration by eddy covariance, sap flow, and FAO-56 methods under different irrigation strategies. J. Irrig. Drain.
Eng. 146:05020002.

Scholander P.F., Bradstreet E.D., Hemmingsen E.A., Hammel H.T. 1965. Sap pressure in vascular plants: negative hydrostatic pressure can be measured in plants. Science 148:339-46.

Swanson R.H., Whitfield D.W.A. 1981. A numerical analysis of heat pulse velocity theory and practice. J. Exp. Bot. 32:221-39.

Vanella D., Cassiani G., Busato L., Boaga J., Barbagallo S., Binley A., Consoli S. 2018. Use of small scale electrical resistivity tomography to identify soil-root interactions during deficit irrigation. J. Hydrol. 556:310-4.

Vanella D., Consoli S. 2018. Eddy covariance fluxes versus satellite-based modelisation in a deficit irrigated orchard. Ital. J. Agrometeorol. 2:41-52.

Vanella D., Ramírez-Cuesta J.M., Intrigliolo D.S., Consoli S. 2019. Combining electrical resistivity tomography and satellite images for improving evapotranspiration estimates of citrus orchards. Remote Sens. 11:373.

Vanella D., Ramírez-Cuesta J.M., Sacco A., Longo-Minnolo G., Cirelli G.L., Consoli S. 2020. Electrical resistivity imaging for monitoring soil water motion patterns under different drip irrigation scenarios. Irrig. Sci. 1-13. 